\title{
Classroom Discourse and Teachers' Experience: A Cognitive View
}

\author{
Bibi Malihe Vamagh Shahi \\ Department of English Language and Literature, Ferdowsi University of Mashhad, Mashhad, Iran
}

\begin{abstract}
In this article, we intend to investigate the role of experience in EFL teachers' discourse using a cognitive taxonomy. In this line, we are going to examine whether there any significant differences between novice and inexperienced groups of teacher in their discourse with regard to a cognitive taxonomy. The selected sample comprises twenty-seven English teachers engaged in EFL classes. Totally, six categories of cognitive processes were introduced. The categories are from the most concrete to the most abstract: (1) knowledge; (2) comprehension; (3) application; (4) analysis; (5) synthesis; and (6) evaluation. According to the results, it was revealed that experienced teachers used more action verbs in all the categories of this taxonomy (428 action verbs out of 805), whereas novice teachers (teachers which has less than 4 years of experience) used 377 action verbs. It can be concluded that experienced teachers teach in more fruitful and meaningful way. Novice teachers can learn and construct meaning from their experiences when they are actively engaged in authentic activity that will help them to learn to think and act in a community of practice.
\end{abstract}

Index Terms - cognitive taxonomy, cognition, discourse analysis, EFL, teachers' talk

\section{INTRODUCTION}

Discourse has been generally described as the utilization of language within social environment (Zarei \& Afshari, 2012). Discourse is more than classroom talk; it is a complicated communication between teacher, students, and these students' unique aspects revealed in verbal interactions (Smart \& Marshal, 2012). The study of teacher discourse is a flourishing and blooming field of inquiry in second language acquisition. The influence of teacher discourse is known to researchers and EFL teachers since it has an important effect on learners' success or failure. Millrood (2004), has investigated the effect of NLP strategies in teachers' discourse on focusing learners toward better understanding and interpreting of the language. He said that it is possible to improve teacher-learner relationship through a suitable verbal interaction with the EFL learners. In the recent decades creating a suitable condition for a productive classroom interaction was the main goal of many teaching researches. Researchers are studying ways of changing teacher discourse from traditional recitation patterns in which the teacher dominates classroom exchanges to more balanced and student-centered communication in which students take a more active role in classroom discourse (Webb et al., 2004).

In the space of educator talk, Cots (1995) accepts that Bringing talk investigation into the language study hall can't be diminished solely to the selection of a progression of new classes and scientific strategies. It requires the educator, in any case, and the understudies, consequently, to take a gander at their instructing and learning task in an altogether different manner: the principle focal point of study isn't language however correspondence (Richards and Rodgers, 2001). Albeit this may seem like an exceptionally clear comment after such countless long periods of having invited to the homerooms the open and notional-utilitarian methodologies, he assumed there still has not been a genuine difference in way to deal with language instructing and learning. The justification this is that, for certain special cases, the etymological instruction of the vast majority of the current language instructors is still particularly impacted by a primary methodology, which focuses on the investigation of language as a self-governing arrangement of rules as opposed to as a method for correspondence. It might in any case require a few years before we begin to see the impacts in the study hall of this new alter of viewpoint which is logically occurring in the phonetic sciences. This change is now reflected in the consolidation of experts in talk investigation and pragmatics in philology divisions and the incorporation of college courses under these titles in the educational programs of future language educators (Cots, 1995). Hymes (as referred to in Cots, 1995), expressed that the main reason includes the acknowledgment that a student's ability to convey in an unknown dialect includes knowing not just (I) regardless of whether and how much a design is officially conceivable (i.e., linguistic), yet in addition whether and how much it is (ii) mentally achievable (i.e., that can be prepared without an incredible exertion), (iii) proper and (iv) really said.

Teachers usually use different discourse strategies to shape the class in the order which they need based on the objectives of the class and the curriculum. When teachers facilitate effective discourse during instruction, they support the development of student understanding and provide a forum for the development of conceptual understanding of scientific constructs (Chin, 2006; Chin, 2007; Mortimer \& Scott, 2003). Teachers can pose questions, engage, and challenge each student's thinking; listening carefully to students' ideas; asking students to clarify and justify their ideas orally and in writing; and monitoring students' participation in discussions and deciding when and how to encourage each student to participate (Webb, Nemer, Kersting, Ing, 2004). 


\section{A. Statement of the Problem}

Teachers' discourse is the most important input in every classroom situation (Inceçay, 2010; Kumaravadivelu, 1999). The view that learning is as the "collection of a series of facts which can be elicited" is much criticized for a long time. Teachers just try to ask some concrete questions and the given response is short and brief, and these questions just show the memorization ability of students. Hattie (2003) claimed a previous pattern of discourse which used by at least some teachers. Initiation, Response, and Evaluation (IRE) have been the "default pattern" or the "unmarked" one which seems to be natural at least to some teachers. In these questions teachers are waiting for a word or a small phrase which can be the correct response. These questions may hinder interaction between teacher and students and also it can have negative effect on students' meaningful learning and prevent growth of critical learners. The fact is that this kind of IRE discourse is suitable just for students with beginning levels of proficiency. Traditional teaching methods are usually characterized by lots of closed questions asked by teachers and little or no interaction between students and teachers. Teachers were asked some questions and evaluate students' knowledge and memorizations skills. In the study by Tsui (1985) she concluded that teacher questions in English classes were predominantly a teacher-centered interaction, or the IRE pattern. The pattern suggested by Van den Oord and Rossem (2002), and during these phases student knowledge was displayed and evaluated.

Up to now, little has been done to scientifically investigate teachers' talk via a cognitive point of view. There were different researches which relied on student proficiency level (Bibi Khan, Inamullah, 2011; Wang \& Farmer, 2008), and also the discourse teachers use in different skills, but I try to add the variable of teacher experience and analyze the discourse teachers in different proficiency levels of classes. Using Bloom's taxonomy this can be one of the first researches which take into account teacher experience variable and how experienced teachers and novice teachers may be different in discourse they use in the class.

\section{B. Significance of the Study}

Meaningful teaching and learning have been long under the attention of scholars and philosophers. Socrates believed that knowledge and awareness were an intrinsic part of each learner. This quote shows that during the teaching history it is of much prominence to help learners to grow mentally and reach into the hidden levels of knowing and awareness. After $1950^{\text {th }}$ and after the development of Bloom's taxonomy, Benjamin Bloom and his colleagues believed that the natural thinking process begins with the lower levels of the Taxonomy, and proceeds to the higher levels. As a matter of fact the only solution for helping learners to learn meaningfully and rationally is stimulating students' abilities of judgment and evaluative capability by employing useful vocabulary for discussing their learning. During the class-time teachers are able to use action verbs which belong to higher-level categories of Bloom's taxonomy and must ensure that students are able to function at higher cognitive levels. The subsequent researches revealed that the discourse of teachers are mostly relied on the lower-level categories (Bibi Khan, Inamullah, 2011; Horner, Zavodska, and Rushing, 2005), and sometimes they believe up to 90 percent of teaching occurs at the knowledge category which is the lowest of Bloom's six levels (Renaud \& Murray, 2007).

The selection of action verbs by teachers is a vital step in the preparation of a useful set of objectives. This study tries to investigate the way teachers try to represent problem-solving abilities as well as higher order processes in the class. Teachers also can design learning activities for use in the classroom and outside of class. In relation to material developers they can consider both higher-level and lower-level processes in their materials and objectives. Finally, the researchers also can use the results of this study for investigating teachers' interaction based on cognitive views.

\section{Research Question}

- Are there any significant differences between novice and inexperienced groups of teacher in their discourse with regard to Bloom's taxonomy?

\section{REVIEW OF THE LITERATURE}

\section{A. Cognitive Psychology and Bloom's Taxonomy}

The first who classified different levels of understanding was Benjamin Bloom (1913-1999); discussions during the 1948 Convention of the American Psychological Association led Bloom to spearhead a group of educators who eventually undertook the ambitious task of classifying educational goals and objectives. Their aim was to develop a method of classification for thinking behaviors that were believed to be important in the processes of learning. Eventually, this framework became taxonomy of three domains:

- The cognitive - knowledge based domain, consisting of six levels

- The affective - attitudinal based domain, consisting of five levels, and

- The psychomotor - skills based domain, consisting of six levels.

In 1956, eight years after the group first began, work on the cognitive domain was completed and a handbook commonly referred to as "Bloom's Taxonomy" was published (Dunegan, n.d.). This study focuses its attention on the cognitive domain. The cognitive domain of Bloom's original taxonomy has six levels organized in a hierarchy. The base of the pyramid is the foundation of all cognition, knowledge. Each ascending level of the pyramid depends on the one below it. Knowledge and comprehension are often referred to as lower-order thinking skills. The skills above them 
are termed higher-order or critical thinking skills. One of the benefits of Bloom's Taxonomy is that it helps teachers identify where they are and where they expect students to be on the pyramid for a particular class or subject. Once a teacher knows this, he can develop learning strategies that are most appropriate, effective, and efficient for the class.

Knowledge level is the lowest-level category which is at the bottom of the hierarchy. Knowledge defines as remembering or retrieving previously learned material. Learning objectives at this level often include defining some key terms, or repeating something heard or seen and as recall of previously learned material. Comprehension symbolizes the largest category of cognitive skills and abilities. The key skill at this level is processing new information. At the application level, a learner is needed to be able to solve a new problem by applying information without having to be prompted. Questions and subjects at this level might require learners to interpret information, demonstrate mastery of a concept, or apply a skill learned. In the Analysis levels students may be asked to distinguish relationships among parts and show decomposition of learned material into its component parts so that its structure may be better understood. Objectives at this level of the hierarchy often include verbs such as differentiate, compare and contrast, criticize, or experiment. At Synthesis level which is the second top highest level teachers ask learners putting parts together, in alternative manners, to form a new whole and produce newly constructed and exceptional products. At this level, objectives might have learners create a table, plan an idea or design a table. The highest level in this pyramid is Evaluation. Evaluation means judging the value of material for a given purpose. Learning objectives and teachers discourse at this level require learners to measure, value, estimate, choose, criticize, justify or revise something, perhaps information, a product - or solve a problem.

Bloom was one of the pioneers of supporting critical thinking. This taxonomy has significance because it was designed for the purpose of designing, assessing, and evaluating student learning. The taxonomy is useful in another way: It allows the teacher to gauge the level of questions asked on the exams. For example, if a question on the test asks students to identify a structure defined in a sentence or shown on a graphic, the teacher knows the query fits in level one, Knowledge. If, on the other hand, students are asked to interpret a graph or predict what would happen if a certain event was to continue, the instructor would realize the question would require more thinking of students and reside in level two, Comprehension. Similarly, a question requiring students to clarify or illustrate a statement would be even more difficult to answer and push the level of difficulty to level three, Application. Questions in the three highest levels are the most difficult to answer. Level four, Analysis, urges students to break down what is asked and examine the meaning of the various sections, while Syntheses (level five) encourages students to combine question elements to solidify understanding. Evaluation, the sixth and most difficult level, requires that students assess the understandings and make recommendations for its utilization (Lord \& Baviskar, 2007; Mortiboys, 2005).

Bloom's Taxonomy has had a profound effect on education and educators, as it provides a mental model for thinking about the relative difficulty of different objectives that students are expected to master and provides guidance for how teachers should approach and assess various objectives. Generally speaking, Bloom's Taxonomy gives teachers a useful vocabulary for discussing their learning objectives.

\section{B. Bloom's Taxonomy and Teachers Discourse}

Questions and use of verbs by teachers are essential components of effective teaching. One of the main purposes of Benjamin Bloom when he started his work was developing a framework for teachers to know how to use the higher order skills. Bloom estimated that the percentage of lower-order assessment questions had been reduced to about 70 percent. By correlating assessment questions to Bloom's cognitive levels, he believed that test developers can ensure that their questions promote both retention of knowledge and critical thinking. One of the basic functions of academics is to use questions to stimulate thinking and reasoning in students and the ability to judge and evaluate the matter (Riding \& Rayner, 1998), while as we can see the teachers in the elementary levels cover the class using action verbs belonging to lower-level processes in Bloom's Taxonomy which mostly assess the retention and memorization abilities of students. The supposition exists that questions identifying with three higher levels of taxonomy should begin to rule the higher scholarly levels in schooling, with a comparing decrease in questions requiring maintenance abilities. It implies that initially levels educators would do well to utilization of action words for evaluating the maintenance and reviewing data. In any case, in the event that we dismiss the higher level cycles it is difficult to make understudies as a basic student and they can't reason viably and to tackle issues inventively. As per Bloom et al. (1956), as educators we will in general pose inquiries in the "information" classification $80 \%$ to $90 \%$ of the time. While these inquiries are not terrible in themselves, utilizing them all the time isn't acceptable practice. These lower-request questions don't consider the conversation of critical thinking methodologies and mental exercises important to react to more unpredictable inquiries. It is desirable over attempt to use higher request level of inquiries. Utilizing these inquiries assist understudies with having the chance to clarify, legitimize, and excuse inside the social setting of the study hall (Chin, 2007). These inquiries require considerably more "intellectual competence" and more broad and elaborate answers.

Wang and Farmer (2008) were anxious to track down the grown-up showing techniques in China, and they attempted to dissect instructors' showing strategies utilizing a creator planned review instrument called Lower-Order Thinking Skills and Higher-Order Thinking Skills (LOTSHOTS). It is utilized to decide if information, appreciation and application drove grown-up showing strategies or examination, blend and assessment drove grown-up showing techniques in China. They based Bloom's taxonomy of instructive destinations and requested that 359 instructors complete the poll. The discoveries showed that Chinese instructors of grown-ups were not acclimated with showing 
higher request thinking abilities related with the three higher levels of Bloom's unique taxonomy as portrayed by investigation, blend and assessment. Specialists presumed that Chinese instructors of grown-ups collectively showed lower request thinking abilities. Chinese educators of grown-ups were accustomed to showing lower thinking abilities related with the initial three levels of Bloom's Taxonomy, specifically, information, appreciation and application. The investigation proposes some potential reasons and ramifications of such practices, and recommends that showing higher request figuring abilities to Chinese grown-up understudies may broaden their frame of reference in connecting all the more transparently in learning.

In a connected report Horner, Zavodska, and Rushing (2005) did an investigation on the consistency of learning destinations with the course level in way of thinking classes. Utilizing Blooms Taxonomy as the standards, learning goals were exposed to content examination. The outcomes showed that lower-level intellectual ability, was the most underscored of the psychological abilities and higher-level cycles which have the most extreme significance in way of thinking was least underlined. Because of the investigation, the school led staff instructional meetings accentuating the significance of creating higher level psychological abilities in understudies by offering suitable intellectual difficulties in the learning targets and in the course content and appraisal related with those goals.

Bibi Khan et al. (2011) did an examination dependent on examination of nature of inquiries in auxiliary level dependent on Bloom's taxonomy. Twenty instructors of various subjects educating at optional level were haphazardly chosen as test of the examination. Instructors were noticed utilizing an observational aide and sound account were directed. The result of the examination showed that the greater part of the inquiries were low-level intellectual inquiries. Among 267 questions67 percent were information based, 23\% were perception based, 7\% were application based, 2\% were investigation based and 1 percent was union based. Anyway the proportion of assessment based inquiries was zero. Albeit this was a useful examination it didn't investigate instructors' sexual orientation, and furthermore the level of students' capability and simply consider middle of the road level.

Another investigation utilizing Bloom's taxonomy is by Webb et al. (2004). They respected the examination of perusing expertise during homeroom time. Taking a few ideas in regards to Neurolinguistic Programming (NLP) which has its premise on growing a worry for the adequacy of correspondence and the irrefutable impact that people can practice on one another through verbal collaboration and finding powerful highlights of language utilized between conversationalists their examination was essentially directed to dissect the nature of talk between two people. They examine instructor talk as indicated by Bloom's psychological model, particularly the activity action words, while showing perusing in EFL setting. The specialists examined the records of sound recorded perceptions to find the nature of instructor talk while introducing understanding exercises and its connection to students' different levels of capability. The outcomes in this investigation uncovered that instructors, particularly in halfway and upper-middle levels, use activity action words that are generally identified with information and perception. At cutting edge level, while showing perusing, instructors have set up a harmony between utilizing information action words and all the more significant level reasoning cycles like assessment. In the end specialists accept educators ought to be worried to build students' knowledge. At the point when students simply get information, they go to buyers; notwithstanding, when their understanding expands, they become makers of information and from this knowledge they would have the option to tackle their own just as the others' issues. This investigation has a few deficiencies, for example, it didn't show a reasonable differentiation between various levels of understudies, it additionally didn't show the distinction between instructors' sexes and how it very well may be diverse in these two.

\section{METHOD}

\section{A. Participants}

\section{Sampling}

Based on Moon (2008), a sample is a group of subjects, or a single subject, from which data are obtained; it is the grouping of subjects chosen from a larger group or population to which the findings are assumed to apply. The process of sampling is very important, and if it is done correctly it can help the researcher to have more valid and relevant information for doing the study.

The sample size depends on the amount of heterogeneity of the population being studied that: the greater the heterogeneity of the population being studied, the larger the sample needed; the more homogeneous the population being studied, the smaller the sample needed. However they do not commit themselves to specific numbers. Since we gathered the data from EFL teachers of Persian, the population of this study is homogeneous.

In this study the aim was based on selecting different teachers with different years of experience and in different proficiency levels. Stratified random sampling used for selecting the teachers. That is, teachers from different strata are selected, which are experienced and novice teachers. There should be equal amount of experienced and novice teachers in the participants. Also, learners' proficiency level was also another criterion for selecting the teachers.

\section{Description of the Sample}

The selected sample comprises twenty-seven English teachers engaged in EFL classes. These classes were classified to nine elementary, nine intermediate and nine advanced classes based on learners' proficiency level. The other 
classification of these teachers is related to teachers' years of experience. These teachers were grouped as thirteen experienced and thirteen novice teachers (one of the teachers was omitted to make the two groups similar in size). Therefore teachers were divided according the years of experience and learners' proficiency level. The criterion for dividing teachers to novice and experienced ones was based on Gatbonton (1999). That is to say that teachers who had taught less than 4 years, are placed in novice category and those who had more than four years of teaching were categorized in experienced group. Teachers were all teaching in three main private institutes in Mashhad-Iran. Teachers were aged from $22-48$

\section{B. Materials}

\section{Coding System}

Totally, six categories of cognitive processes were introduced by Bloom et al. (1956). The categories are from the most concrete to the most abstract: (1) knowledge; (2) comprehension; (3) application; (4) analysis; (5) synthesis; and (6) evaluation. Table 1 shows Bloom's taxonomy with the definition of each level, the roles students should perform and examples for action verbs. Table 1 is used as the coding system for the data.

TABLE 1

BLOOM'S COGNITIVE TAXONOMY OF THINKING PROCESSES

\begin{tabular}{|l|c|c|}
\hline Level of Taxonomy & Definition & Action Verbs examples \\
\hline Knowledge, (The most concrete) & Recall of specific information & Tell, Define, name, list, describe \\
\hline Comprehension & Understanding of communicated information & Change, Describe, explain, rewrite, translate \\
\hline Application & Use of rules and theories in new situations & Apply, Demonstrate, respond, employ, practice \\
\hline Analysis & Breaking down information into parts & Investigate, Categorize, distinguish, select \\
\hline Synthesis & Putting together of ideas into a new plan & Create, Invent, combine, arrange, reorganize \\
\hline Evaluation(The most abstract) & Judging the value of materials or ideas & Decide, Assess, judge, evaluate, summary \\
\hline
\end{tabular}

This category is a model for analyzing teachers' discourse. That is, every teacher's action verb in different classes were identified and then placed in each specific level of taxonomy. The action verbs which are used by the teachers are from the action verbs which are mentioned in Table 1. For example, one teacher may use the sentence 'compare these two pictures'. The action verb of this sentence is to compare. Therefore, in teachers' discourse there are a variety of action verbs and it is possible to find out and analyze these action verbs.

\section{Transcriptions of the Data}

Teachers' discourse was observed and audio-recorded by the researcher as an observer of the classes. McMillan and Schumacher (1993, p. 256) stated that as a participant observer the researcher should first make judgment before entering the observation field (that is, high inference observation, and then, in the field: record the specific behaviors and context that led to the inference implied in judgment). The verbatim transcript of the recorded lesson of these audiorecorded sentences was the main material of this study. The transcriptions allowed us to identify the action verbs teachers used in the course of teaching. The total number of action verbs was 824. As it is related to experienced teachers, 428 action verbs were identified and 377 verbs were related to novice teachers. Table 2 summarizes the variables and the amount of action verbs related to each.

TABLE 2

Distribution Of ACTION VERBS BASEd ON LEARNERS' PROFICIENCY LEVEL, AND TEACHERS' EXPERIENCE

\begin{tabular}{|l|l|l|l|}
\hline \multirow{2}{*}{ Learners' Proficiency Level } & \multicolumn{3}{|l|}{ Teachers' Classification based on the Frequency of Action Verbs } \\
\cline { 2 - 4 } & Elementary & Intermediate & Advanced \\
\cline { 2 - 5 } & 244 & 273 & 307 \\
\hline \multirow{2}{*}{ Teachers' Experience } & Novice & Experienced \\
\cline { 2 - 4 } & 428 & 377 & \\
\hline
\end{tabular}

\section{Design of the Study}

This study will be embedded in both qualitative and quantitative approach. The qualitative part is related to collecting, analyzing, and interpreting data by observing what people do and say. The coding of the data is related to qualitative part of this study. The data gathering tool was observation of the classes. Based on Peregroy and Boyle, (2005), the advantage of this method over other methods is that the researcher does not have to rely on the willingness and ability of the participants to report information accurately but on human behavior always bound to the context in which it occurs and that social reality cannot be reduced to variables as quantitative researchers would have it. The quantitative section of the study is related to analyzing the significance of the categories in different variables by Chi-square.

There are several methods in hand for researcher to collect empirical materials, ranging from interview to direct observation, to the analysis of artifacts, documents, and cultural records, to the use of visual materials or personal experience. Faced with large amounts of qualitative materials, the investigator seeks ways of managing and interpreting these documents, and here data management methods and computer-assisted models of analysis may be of use (Denzin and Lincoln, 1994, p. 14). 


\section{Procedure}

This research was aimed at investigating teachers' discourse based on Bloom's taxonomy. This study was conducted during summer 2013 and took almost three months. Observation of the classes by the researcher as a participantobserver and audio-recording teachers' voice were the main ways to gather data. Observation of the phenomenon under investigation has little restrictive effect on the way data is gathered. In class observation, the researcher would benefit from dynamic and immediate involvement of the teacher with the students as these teachers use a variety of different materials in their discourse and the performance of teachers may be evaluated by direct observation and audio-recording of classes. In the first phase of the study, 27 classes were observed and the verbs teachers had used were identified and analyzed. The Bloom's cognitive taxonomy was used for coding and categorizing of these verbs. In the second phase of this research, the verbs teachers used were categorized based on experience and learners' proficiency level and the verbs were placed in one of the related six categories of Bloom's cognitive taxonomy. For the purpose of comparing between different levels and in different groups, the frequency of each of these groups and the percentage of the verbs in different six categories were calculated.

\section{E. Data Analysis}

To analyze the data obtained from observing classes, frequency count and Chi-square formula were used. Each action verb is counted and accumulated. Then, to find out the significance of differences, Chi-square formula is utilized. The Chi-square test applies only to examine the significance of differences between two (or more) nominal-level variables (those expressed in frequency counts). The test is based upon the concept of independence the idea is that one variable is not affected by, or related to another.

\section{RESUlTS}

This part deals with the distribution of action verbs and analyzing the differences which exist between different groups of teachers. In the first part, teachers' use of action verbs was analyzed based on the proficiency level of classes. The teachers discourse was analyzed and the action verbs teachers used in different levels were placed in different categories of Bloom's taxonomy and each level was investigated one by one. In the next part of this section these teachers were placed in two groups: experienced and novice teachers and the analysis of teachers discourse in these two groups were taken into consideration. Evaluating action verbs with focusing on the teachers' experience as well as how experienced and novice teachers can be different regarding the use of action verbs.

\section{A. Teachers' Experience}

After presenting the results of proficiency level and its role on teacher discourse we will examine how the teachers' experience can be related to the quality of teacher discourse. The criterion proposed by Gatbonton (1999) was set as the basis for classifying teachers. He made a distinction between novice and expert teachers in his study. He categorized experienced teachers as the teachers who have more than four years of teaching experience (Gatbonton, 1999). Consequently in this research teachers are divided into two groups of experienced (more than four years of teaching experience) and novice teachers (less than four years of teaching experience).

For the sake of similarity of the two groups and to be able to show that the differences in the use of action verbs are related to the situation of the classes and not to the number of subjects, one of the experienced teachers was omitted and the 26 teachers were categorized in the two groups of experienced and novice teachers (13 experienced and 13 inexperienced). As two groups are placed for the study of the role of experience in teacher discourse one of teachers was omitted to bring equality in number between two groups of experienced and novice teachers.

\section{Experienced Teachers}

Thirteen out of twenty-six classes were taught by experienced teachers, teachers with more than four years of experience. Most of these teachers have been teaching English in EFL Persian context for about five months to eighteen years. The total proportion of action verbs were used by these experienced teachers was 429 out of 805 action verbs. The novice teachers used the majority numbers of action verbs at the elementary levels, including mostly lower-level thinking processes. It is clear that the experienced teachers used the majority of action verbs compared with novice teachers. 
TABLE 3

DISTRIBUTION OF TEACHERS’ ACTION VERBS IN EXPERIENCED AND NOVICE TEACHERS

\begin{tabular}{|l|c|c|}
\hline \multirow{2}{*}{ Teacher experience } & Used by Experienced & $\begin{array}{c}\text { Used by } \\
\text { Novice }\end{array}$ \\
\cline { 2 - 3 } & Frequency & Frequency \\
\hline Knowledge & $\mathbf{1 2 1}$ & $\mathbf{1 3 9}$ \\
\hline Comprehension & $\mathbf{1 0 3}$ & $\mathbf{1 0 2}$ \\
\hline Application & $\mathbf{5 4}$ & $\mathbf{7 2}$ \\
\hline Analysis & $\mathbf{4 9}$ & $\mathbf{2 4}$ \\
\hline Synthesis & $\mathbf{5 7}$ & $\mathbf{3 3}$ \\
\hline Evaluation & $\mathbf{4 4}$ & $\mathbf{7}$ \\
\hline Total & $\mathbf{4 2 8}$ & $\mathbf{3 7 7}$ \\
\hline
\end{tabular}

It is true that experience is an important factor gained over time, which enhances the knowledge, skills, and productivity of teachers. As it can be concluded from Table 3., the action verbs used by these two groups are different. The experienced teachers used 428 sentences containing action verbs whereas 377 action verbs were used by the novice teachers. By examining Table 3, it can be concluded that novice teachers tend to use more low-level action verbs such as 'tell, describe, repeat' vis-à-vis other related verbs in lower-level categories. The quantity of action verbs is decreased in the novice group, i.e. higher in the pyramid concerned with the higher-level thinking categories. The percentage of lower-level action verbs used by novice teachers is about 53\%, i.e., a number much higher than the percentage used by novice teachers higher-level thinking categories (30\%). So the results suggest that experienced teachers tend to be much more skillful in using higher-level thinking processes and implementing critical thinking skills in the classes. They used about $70 \%$ of higher-level action verbs and about $53 \%$ of total action verbs (428 out of 805 ).

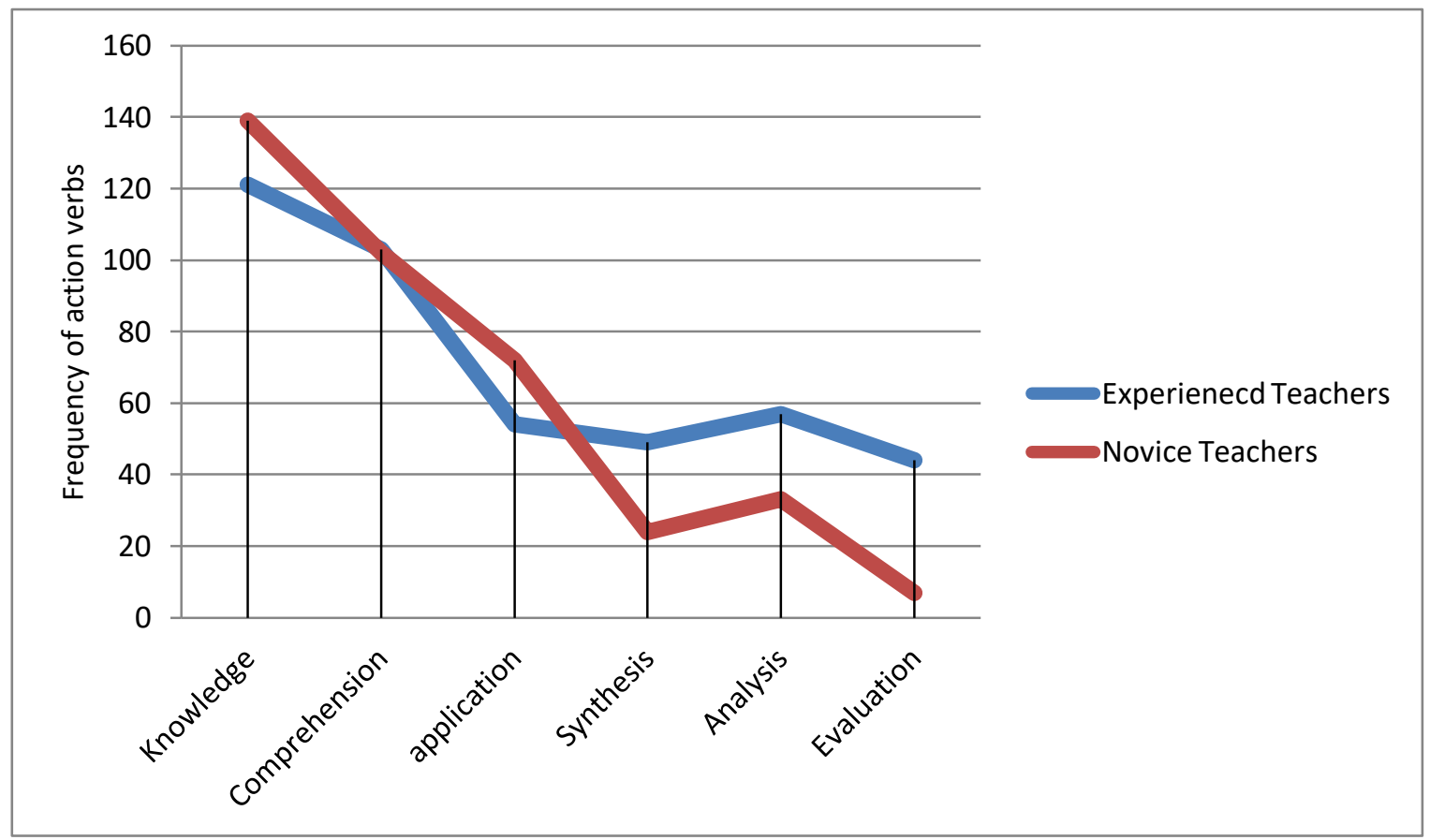

Figure 1. Frequency of action verbs used by the Experienced and inexperienced teachers

As Fig. 1 illustrates, the blue line which relates to the experienced teachers stands in higher positions in three highestlevel categories of Bloom's cognitive taxonomy. This figure shows that experienced teachers' discourse contains higher-level thinking processes compared with novice teachers. However, novice teachers used a great number of lower-level action-verbs (313 lower level action verbs compared with 278 low-level action verbs used by experienced teachers). The point that should be taken into account is that one considers the three higher level thinking categories in Figure 1 it is apparent that the use of action verbs by the experienced group in these three categories is varied. Concerning the category analysis, the action verbs by the experienced teachers' group were 49 out of 24 action verbs used by the novice teachers. The variation in numbers is followed in the next two categories, that is the synthesis 57 versus 33, and the most difference in these two groups belong to evaluation, which in the experienced group is 44 compared with 7 action verbs, suggesting that experienced teachers tend to be more careful about higher-level thinking verbs, critical thinking and problem-solving methods. It is clear that there is no balance between usage of different action verbs categories in both experienced and novice teachers (the total amount of higher-level action verbs are still low), between different categories of taxonomy, but the percentage of higher-level action verbs in experienced group is about 35\% which is much higher than the percentage of higher-level action verbs in novice teachers (17\%). 


\section{Novice Teachers}

As it is a belief that novice teachers are well-trained in the latest research and teaching techniques, giving students the best chance to meet today's rigorous educational standards, and bring a fresh energy to the classroom. But the results show that experienced teachers tend to be more aware of the complexity and have more enriched conceptual repertoires regarding teaching than novice teachers. They are mostly concerned with using action verbs in the class, monitoring students during the class-time, and encouraging students to think critically (the results show that in higherlevel categories experienced teachers' use of action verbs is much higher than the novice teachers).

TABLE 4

THE SIGNIFICANCE OF DIFFERENCES BETWEEN EXPERIENCED AND INEXPERIENCED TEACHERS’ ACTION VERB

\begin{tabular}{|c|c|c|c|c|c|c|}
\hline category & Experienced & Novice & Expected & df & $\chi^{2}$ & Sig. \\
\hline Knowledge & 121 & 139 & 130 & 1 & 1.246 & .264 \\
\hline Comprehension & 103 & 102 & 102.5 & 1 & .944 & .005 \\
\hline Application & 54 & 72 & 63.0 & 1 & 2.571 & .109 \\
\hline Analysis & 49 & 24 & 36.5 & 1 & 8.562 & .003 \\
\hline Synthesis & 57 & 33 & 45.0 & 1 & 6.400 & .011 \\
\hline Evaluation & 44 & 7 & 25.5 & 1 & 26.843 & .000 \\
\hline
\end{tabular}

As it is shown in Table 4, there is a significant difference between different categories of the table concerning experienced and novice teachers except for knowledge and application which are not significant (.264, .109). That is to say, novice and experienced teachers are not significantly different in the distribution of knowledge and application verbs. The difference is not attributable to teachers' experience but other factors such as the topic of the lesson, students' qualities, etc.

\section{B. Summary}

The data showed that the use of higher level thinking processes is mostly viewed in advanced levels. That is to say, teachers in advanced classes asked students to use their higher-order thinking process more than what is seen in elementary and intermediate levels. The use of lower-level thinking processes which is knowledge and comprehension are mostly seen in elementary and intermediate classes although in intermediate levels more higher-order processes are utilized and observed. Moreover, experienced teachers used more verbs related to evaluation and synthesis which is a manifestation of more productivity and interaction of mental complexities. One justification is that in elementary levels, learners are not good input generators and teachers resort to lower processes to allow learners to avoid cognitive load. That is, there may be a relation between language and mind which is advocated by Vygotsky and his followers (Hausfather \& Samuel, 1996).

\section{CONCLUSION}

Another area which has been taken into account in this study is the role of experience in teachers' use of action verbs. By comparing novice and experienced teachers' instructional activities in the classroom, one can have a better understanding of the development of teaching expertise and how this expertise may be effective on teachers discourse. There is a lot of controversy over this issue and a lot of research is done on this topic. Since teachers usually gain extensive experience of successful and unsuccessful performances throughout their years of teaching, this assumption has generated that experience promotes teacher's effectiveness and help students attain higher levels of achievements. There are other views like Gorrell and Dharmadasa (1994) beliefs, which is in the same line with the results of this study indicating that although experienced teachers were more concerned about classroom management and organization of instruction and their impacts on students, novice teachers preferred implementing new methods of instruction.

The question of this study was related to differences between novice and experienced teachers. With regard to this question we took into account the differences between novice and inexperienced teachers with regard to cognitive taxonomy. It was revealed that experienced teachers used more action verbs in all the categories of cognitive taxonomy (428 action verbs out of 805), whereas novice teachers (teachers which has less than 4 years of experience) used 377 action verbs. The findings of this study revealed that novice teachers used more action verbs related to knowledge and application, and there is an equal quantity between these groups in comprehension category. Experienced teachers reflect and evaluate teaching and learning in a more effective way, talk much more than novice teachers, communicate creatively, and have instruction plans. These experienced teachers used action verbs in a more balanced way than novice teachers. They ask higher quantity of "higher-order" questions, the kinds of questions which promote learning, because these types of questions require students to apply, analyze, synthesize, and evaluate information instead of simply recalling facts. It is better to use the following strategies at advanced levels: which is quoted in Hattie, (2003):

- Identifying essential representations of their subject

- Guiding learning through classroom interactions

- Monitoring learning and providing feedback

- Attending to affective attributes 
- Influencing student outcomes (p. 5)

When we put our emphasis on the quantity of action verbs in higher-level categories of Bloom et al.'s (1956) taxonomy the results are completely different in two groups. As Table 4 demonstrates, experienced teachers use 150 action verbs in three higher-level thinking skills, versus 64 action verbs used by novice teachers. Expert teachers (especially in intermediate and advanced group) tend to monitor their ongoing solution attempts, checking for accuracy, and updating or elaborating problem representations as new constraints emerge. Flexibility is one of the main characteristics of expert teachers which existed in classes with experienced teachers. They are trying to invoke problemsolving, critical thinking and the skill of analyzing and evaluation besides knowledge and comprehension of students.

There are different studies which are in the same line with this study, considering the effects of teacher experience on student learning and relationship between teachers' effectiveness and their years of experience. As it is deducted from Table 4 novice teachers used simple, low-level questions. It is crystal clear that experienced teachers are in higher sophisticated teaching level, use much more action verbs in their discourse, and are more reflective and active in the class. Morine (1973), as well, stated that it is a kind of stereotyped action of the teacher when not engaged in thinking. By the use of routines, experienced teachers are better in attending other simultaneous events occurring in the classroom. Berliner (1986) believed that expert teachers used routines to record attendance, to handle chorus responding, to start lesson segments, and so on. Another matter which is important and can be seen more in experienced teachers in this study is problem representation which is one aspect of cognition Problem representation means the mental construction, preservation and interpretation of information of real world object and events. These representations, dependent on their complexity and sophistication, may constrain the mental processes associated with abilities such as perceiving, inferring, assuming, and recognizing situations and phenomena. With regard to the results, it can be concluded that experienced teachers teach in more fruitful and meaningful way. Novice teachers can learn and construct meaning from their experiences when they are actively engaged in authentic activity that will help them to learn to think and act in a community of practice.

\section{REFERENCES}

[1] Berliner, D. C. (1986). In pursuit of expert pedagogue. Educational Researcher, 15(7), 5-13.

[2] Bibi Khan, W., \& Inamullah, H. M. (2011). A study of lower-order and higher- order questions at secondary level. Asian Social Science, 7(9), 149-157.

[3] Bloom, B. S., Engelhart, M. D., Furst, E. J., Hill, W. H., \& Krathwohl, D. R. (1956). Taxonomy of educational objectivesHandbook 1: The cognitive domain. New York: David Mackey.

[4] Chin, C. (2006). Classroom interaction in science: Teacher questioning and feedback to students' responses. International Journal of Science Education, 28(11), 13-15.

[5] Chin, C. (2007). Teacher questioning in science classrooms: Approaches that stimulate productive thinking. Journal of Research in Science Teaching, 44(6), 8-15.

[6] Cots, J. M. (1995). Bringing discourse analysis into the language classroom. Departament d'Angles i de LingüísticaUniversitat de Lleida.

[7] Denzin, N. \& Lincoln, Y. (1994). Handbook of qualitative research. Thousand Oaks, CA: Sage.

[8] Dunegan, L. (n.d). An investigation of multiple intelligences: Developing an indicator of learning styles for vocational education and traditional students (Doctoral dissertation, Capella University).

[9] Gatbonton, E. (1999). Investigating experienced ESL teachers' pedagogical knowledge. Modern Language Journal, 83(1), 3550 .

[10] Gorrell, J., \& Dharmadasa, H. (1994). Perceived self-efficacy of pre-service and in service Sri Lankan teachers. International Education, 24, 23-36.

[11] Hattie, J. A. (2003). Teachers make a difference what is the research evidence? Australian Journal of Educational Research, 36, 5-13

[12] Hausfather, S., \& Samuel, J. (1996). Vygotsky and Schooling: Creating a Social Contest for learning. Action in Teacher Education, 18, 1-10.

[13] Horner, R., Zavodska, A., \& Rushing, J. (2005). How challenging? Using Bloom's taxonomy To assess learning objectives in a degree completion program. Journal of College Teaching \& Learning, 2(3), 48-52.

[14] Inceçay, G. (2010). The role of teacher talk in young learners' language process. Procedia Social and Behavioral Sciences, 2 , 277-281.

[15] Kumaravadivelu, B. (1999). Critical classroom discourse analysis. TESOL Quarterly, 33(3), 453-484.

[16] Lord, T., \& Baviskar, S. (2007). Moving students from information recitation to information understanding: Exploiting Bloom's taxonomy in creating science questions. Journal of College Science Teaching, 12 (2), 34-65.

[17] McMillan, J. H. \& Schumacher, S. (1993). Research in education: A conceptual framework. New York: Harper Collins College Publishers.

[18] Millrood, R. (2004). The role of NLP in teachers' classroom discourse. ELT Journal, 58, 28-37.

[19] Moon, J. (2008). Critical thinking: An exploration of theory and practice. NY: Routledge.

[20] Morine, G. (1973). Planning skills: paradox and parodies. Journal of Teacher Education, 2, 135-143.

[21] Mortiboys, A. (2005). Teaching with emotional intelligence: a step-by-step guide for higher and further education professionals. New York, NY: Taylor \& Francis.

[22] Mortimer, E., \& Scott, P. (2003). Meaning making in secondary science classrooms. Maidenhead, Berkshire: Open University Press.

[23] Peregroy, S., \& Boyle, O. (2005). Reading, writing, and learning in ESL: A resource book for K-12 teachers. Boston: Allyn \& 
Bacon.

[24] Renaud, R., \& Murray, H. (2007). The validity of higher-order questions as a process indicator of educational quality. Research in Higher Education, 48(3), 311-331.

[25] Smart, J. B., \& Marshall, J. C. (2012). Interactions between classroom discourse, teacher questioning, and student cognitive engagement in middle school science. The Association for Science Teacher Education, USA.

[26] Tsui, A. B. M. (1985). Analyzing input and interaction in second language classrooms. RELC Journal, 16(1), 8-32.

[27] Van den Oord, E. J., \& Rossem, V. (2002). Differences in first graders' school adjustment: The role of classroom characteristics and social structure of the group. Journal of School Psychology, 40(5), 371-394.

[28] Wang, V., \& Farmer, L. (2008). Adult teaching methods in China and Bloom's taxonomy. International Journal for the Scholarship of Teaching and Learning, 2(2), 1-15.

[29] Webb, N. M., Nemer, K. M., Kersting, N., \& Ing, M. (2004). The effects of teacher discourse on student behavior in peerdirected groups. Annual meeting of the American Educational Research Association: San Diego.

[30] Zarei, A., \& Afshari, S. N. (2012). Experienced and novice Iranian teachers' perceptions as to the effect of intrinsic factors on teacher efficacy. Basic Research Journal of Education Research and Review, 1(1), 4-14

Bibi Malihe Vamagh Shahi is a PhD candidate of TEFL at the Department of English Language and Literature at Ferdowsi University of Mashhad, Mashhad, Iran. She does research on English language teaching and applied linguistics. She also publishes on second language writing. 